visit was an influx of British and French wounded all hit, so to speak, above the belt, in the head and chest. The conclusion drawn by all the French and Americans who witnessed his conduct is that he came here solely to correct the elevation of the German rifles. From what I have seen of the German wounded our side stands in no need of any such correction, but I am glad to believe that nó French or British army surgeon would lend himself to such calculations, so unworthy of our profession.

I should like to add that operating surgeons are much needed in advanced ambulances such as this where wounded in urgent need of operation arrive daily. British or other surgeons willing to take a turn of this duty, if even for only a week or two, will be as heartily welcomed as I have been. They should apply preterably to La Croix Rouge Française, 21, Rue François $I^{\text {er }}$, Paris. I expect to be at $\mathrm{my}$ London address (6, Manchester-square, W.) on Sept. 25th, and should be happy to give them any assistance in my power.

A French friend starting for the coast has kindly undertaken to find someone who will post this in London. I am, Sir, yours faithfully,

JAMES DONELAN.

Ambulance de la Croix Rouge Francaise, Crépy-en-Valois, Sept. 9th, 1914 .

\section{ORAL AND AURAL SEPSIS.}

To the Eiditor of THE LANCET.

SIR,--The public should by now be well informed as to the dangers of oral sepsis. I can endorse Mr. Morton Smale's remarks in his sensible letter in THE LANCET of Sept. 12th as to the way people discuss pyorrhcea. Septic auto-inoculation, however, in its severe forms is more commonly the result of neglected ear disease. Neither the public nor the profession seem as yet to appreciate fully the importance of ear infection. The mouth is constantly being washed out, so to speak, the ear only by syringing, often badly done. How many of our soldiers have gone to the front with infected ears! I am, Sir, yours faithfully,

Wimpole-street, W., Sept. 11th, $1914 . \quad$ F. FAULDER WHITE.

\section{THE BRITISH PHARMACOPCEIA. To the Editor of THE LANCET.}

SIR,-At its meeting on Sept. 15th the Executive Committee of this Council received a report by the Registrar on the postponement of publication of the British Pharmacopœia, 1914, which had been rendered necessary by the events of the last month.

It was resolved by the committee, on behalf of the Council, that copies in advance of publication should be made accessible to the public for inspection at the offices of the Council in London, Edinburgh, and Dublin on Thursday, Oct. 1st, 1914, at 10 A.M., and thereafter from 10 A.M. to 4 P.M. daily, and that a copy for review should on the same day be placed in the hands of the editor of each of the medical and pharmaceutical journals in the Registrar's list.

The official publication of the work will be made by notices in the Gazette on Thursday, Dec. 31st, 1914, on which day copies will be on sale at the price of 10s. $6 d$. net, by the publishers, Messrs. Constable and Co., Limited, 10, Orange-street, Leicester-square, London, W.C.

$$
\text { I am, Sir, yours faithfully, }
$$

A. J. Cockington, Acting Registrar.

General Council of Medical Education and Registration of the United Kingdom, Oxford-street, London, W Sept. 22nd, 1914.
CITY OF LONDON TERRITORIAL FORCE: VACANCIES FOR MEDICAL OFFICERS.

\author{
To the Editor of THE LANCET.
}

SIR,-In accordance with the orders of the Secretary of State for War it has been decided to raise reserve units of the Territorial Force. Consequently, there are vacancies for a number of medical officers in the Royal Army Medical Corps uuits of the 1st London Division. These are the 1st, 2nd, and 3rd Field Ambulances, and a Sanitary Company.

Gentlemen who desire commissions should apply by letter in the first instance to the secretary of the City of London Territorial Force Association, Friars House, New Broad-street, E.C.

I am, Sir, yours faithfully,

W. CAMPBELL HYSLOP,

Sept. 22nd, 1914 Lieutenant-Colonel, Secretary.

University of Birmingham : Faculty of MEDICINE. - The opening ceremony, which was to have been held in the first week of October, and for which a medical and biological kinematograph demonstration had been arranged by Messrs. Pathé Frères, has been cancelled owing to the war.

Poor-law Medical Officers' Association of ENGLAND AND WALES. - A council meeting of this association was held at 34, Copthall-avenue, E. C., on Sept. 14th, SurgeonGeneral G. J. H. Evatt being in the chair. With regard to the appointment of a delegate to represent the association at the Congress of Social Work and Service in 1915 it was agreed that this should be postponed. The honorary secretary reported that the attempt of the Isle of Wight guardians to vary the Poor-law Orders by authorising individual guardians to grant medical orders in cases of emergency had not succeeded. A letter was read from the Local Government Board acknowledging the receipt of a copy of the council's report on the Poor-law Institutions' Order (1913). The honorary secretary said that this report had been widely circulated and had met with general approval. With regard to the Burnley dispute, the honorary secretary reported that mainly owing to the war the local profession at Burnley had decided to come to a temporary agreement with the guardians and support their arrangements for medical relief in the union till the political atmosphere became clearer, so that a temporary agreement had been come to which might possibly result later in a final one. The council unanimously approved of what had been done. The honorary secretary reported that he had been informed that the Bethnal Green guardians were approaching the Local Government Board with a view of abolishing their present district medical officers and replacing them by whole-tine medical officers resident at the infirmary. He thought that the association should strongly oppose this project. There were no special reasons for such a change in the Bethnal Green area, and the interests of the sick poor were much better safeguarded by the present system. The council were unanimously opposed to extending the Bermondsey scheme to other districts. In a discussion on the effect of the war on the work of the Poor-law medical officers it was thought by the council that this work would be considerably increased. There had been large funds collected to meet the needs of dependents of those engaged in the military and naval service of the country; notwith. standing a considerable portion of the medical attendance on this class would probably be given in one way or another by Poor-law medical officers. Then there would be those thrown out of work by the war and their dependents. Already the number of medical orders issued in various unions had been greatly increased. It was agreed that it was the duty of all Poor.law medical officers to do their utmost to assist any of their brethren who were called upon, or had volunteered, to assist the State in carrying on the war ; but if Poor-law medical officers were employed to attend on sickness arising among German prisoners of war it was only right that extra payment should be made them for such services. 